\title{
PERSPECTIVA HISTÓRICA EM ADMINISTRAÇÃO: NOVOS OBJETOS, NOVOS PROBLEMAS, NOVAS ABORDAGENS
}

\author{
HISTORICAL PERSPECTIVE IN MANAGEMENT: NEW OBJECTS, NEW PROBLEMS, NEW APPROACHES \\ PERSPECTIVA HISTÓRICA EN ADMINISTRACIÓN: NUEVOS OBJETOS, NUEVOS PROBLEMAS, NUEVOS ABORDAJES
}

\section{RESUMO}

A pesquisa busca contribuir para uma melhor compreensão do pensamento administrativo por meio da análise da utilização da perspectiva histórica em administração. Embora a aproximação entre administração e história não seja recente, ainda não avançou substancialmente de forma a viabilizar seu potencial ontológico, epistemológico e metodológico. De forma a aprofundar essa discussão, classificamos três abordagens do pensar administrativo relacionando-as com a discussão paradigmática da história, quais sejam: a história dos negócios (business history); a história da gestão (management history); e a história organizacional (organizational history). Tal enquadramento permitiu identificar que a perspectiva histórica da nova história inserida numa posição reorientacionista possibilita: a) refletir sobre a práxis social do pesquisador; b) considerar novos objetos, problemas e abordagens de pesquisa; e c) perceber que novas perguntas podem deslocar o foco de análise do exógeno para o local, o que contribui para o desenvolvimento de análises mais críticas sobre ideologias administrativas.

PALAVRAS-ChAVE Pesquisa em administração, perspectiva histórica, história dos negócios, história da gestão, história organizacional.

Alessandra de Sá Mello da Costa amello9@terra.com.br

Doutoranda pela Escola Brasileira de Administração Pública e de Empresas, Fundação Getulio Vargas - Rio de Janeiro - RJ, Brasil

Denise Franca Barros denise.barros@fgv.br

Doutoranda e professora da Escola Brasileira de Administração Pública e de Empresas, Fundação Getulio Vargas - Rio de Janeiro - RJ, Brasil

\section{Paulo Emílio Matos Martins pemiliom@fgv.br}

Professor da Escola Brasileira de Administração Pública e de Empresas, Fundação Getulio Vargas - Rio de Janeiro - RJ, Brasil

Recebido em 15.11.2009. Aprovado em 27.05.2010

Avaliado pelo sistema double blind review

Editor Científico: Rodrigo Bandeira-de-Mello

\begin{abstract}
This article attempts to contribute to a better understanding of administrative ideas through the analysis of the use of historical perspective in management studies. Although this relationship is not recent, it has not progressed substantially in order to promote all their ontological, epistemological and methodological potential. In order to deepen this discussion, we classify three management approaches relating them to the paradigmatic discussion of history: business history, management history and organizational history. This framework allows us to consider that the reorientationist position of the historical perspective enable us to: a) reflect on the social praxis of researchers, $b$ ) consider new objects, new problems and new research approaches, and c) realize that new questions displaces the focus of analysis of the exogenous to the local, which may contribute to the development of more critical analysis of current administrative ideologies.
\end{abstract}

KEYWORDS Management research, historical perspective, business history, management history, organizational history.

RESUMEN La investigación busca contribuir a una mejor comprensión del pensamiento administrativo por medio del análisis de la utilización de la perspectiva histórica en administración. Aunque la aproximación entre administración e historia no sea reciente, todavía no avanzó sustancialmente como para viabilizar su potencial ontológico, epistemológico y metodológico. A los efectos de profundizar ese debate, clasificamos tres abordajes del pensar administrativo, relacionándolos con el debate paradigmático de la historia, ellos son: historia de los negocios (business history); historia de la gestión (management history); e historia organizacional (organizational history). Tal encuadramiento permitió identificar que la perspectiva histórica de la nueva historia insertada en una posición reorientacional posibilita: a) reflexionar sobre la praxis social del investigador; b) considerar nuevos objetos, problemas y abordajes de investigación; y c) percibir que nuevas preguntas pueden desplazar el foco de análisis -del análisis exógeno al análisis local-, lo que contribuye al desarrollo de análisis más críticos sobre ideologías administrativas.

PALABRAS CLAVE Investigación en administración, perspectiva histórica, historia de los negocios, historia de la gestión, historia organizacional. 


\section{INTRODUÇÃO}

Esta pesquisa busca contribuir para uma melhor compreensão do pensamento administrativo por meio da análise de como a perspectiva histórica (ÜSDIKEN e KIESER, 2004) vem sendo utilizada nos estudos de Administração. Essa perspectiva tem despertado o interesse de vários acadêmicos, no Brasil e no exterior (KIESER, 1994; CURADO, 2001; TUCHMAN, 2003; CLARK e ROWLINSON, 2004; JACQUES, 2006; SAUERBRONN E FARIA, 2006; MAIELLI, 2007; VIZEU, 2007; 2010; MAIELLI e BOOTH, 2008; MASCARENHAS e VASCONCELOS, 2009).

No Brasil, destacamos como aspectos mais significativos desse interesse: a) a busca de maior relevância e contribuição teórica das pesquisas por meio da ampliação do uso do método histórico; b) o resgate dos aspectos históricos e interculturais em oposição à reprodução ideológica dominante que tende a excluir o passado ou o contexto das teorias e práticas organizacionais (VIZEU, 2007); e c) a aproximação dos pesquisadores ao contexto da realidade brasileira potencializando uma posição de engajamento e compromisso consciente com sua realidade social (GUERREIRO RAMOS, 1996).

A ideia é que a pesquisa histórica contribua para fundamentar pesquisadores que buscam novos olhares e estejam comprometidos com outras epistemologias, expandindo as possibilidades de análise e teorização acerca do espaço organizacional, entendido aqui não como um espaço físico, mas como um campo objeto de estudo da análise organizacional e de sua dinâmica (MARTINS, 2001). Algumas tentativas nessa direção podem ser identificadas por meio da utilização de arcabouços teóricos de autores provenientes de outras áreas, como Norbert Elias (BERJARANO, PILATTI, FRANCISCO e OLIVEIRA, 2005), Pierre Bourdieu (MISOZCKY, 2004), Michel Foucault (CARRIERI, PIMENTEL e CABRAL, 2005), Clifford Geertz (JAIME JUNIOR, 2001), Sérgio Buarque de Holanda (MOTTA, ALCADIPANI, BRESLER, 2000), Gilberto Freyre (LACOMBE, 2000), Marshall Sahlins (MASCARENHAS e VASCONCELOS, 2009) entre outros. Tais tentativas, no entanto, ainda se apresentam numericamente incipientes quando inseridas no contexto maior do campo acadêmico da Administração no Brasil. Apesar dos esforços desses pesquisadores, ainda não existem associações, centros de pesquisa, periódicos especializados ou espaço exclusivo para discussão em congressos nacionais acerca da perspectiva histórica em Administração.

Defendemos a incorporação da perspectiva histórica como contribuição para o avanço na análise de fenômenos administrativos por meio do enriquecimento e ampliação das pesquisas, tanto pela adoção de quadro teórico-conceitual constituído a partir da análise histórica quanto pela aplicação da pesquisa histórica como método de análise (VIZEU, 2007).

As organizações foram racionalmente projetadas para resolver conflitos entre as necessidades coletivas e as vontades individuais (REED, 1999), e seu processo de ação e criação foi realizado necessariamente por indivíduos em um específico contexto histórico. Identificar e analisar esse contexto, por meio de quadro teóricoconceitual constituído a partir da perspectiva histórica, contribui para que o pesquisador evite atribuir caráter ahistórico e determinístico aos estudos, o que pode levar, por exemplo, a anacronismos. Isto é, levam à utilização de conceitos e ideias de uma época para analisar fatos de outro tempo histórico, provocando distorções metodológicas, distanciando acontecimentos e sublinhando uma intemporalidade universal.

Ao questionar tal intemporalidade, o pesquisador também questiona a visão de organizações como unidades independentes e autônomas que poderiam prescindir de avaliação moral ou de debates políticos (GOULDNER, apud REED, 1999). Por outro lado, a pesquisa histórica como método de análise contribui ampliando os possíveis objetos de pesquisa por meio de novas fontes, problemas e abordagens.

A aproximação entre administração e história não é recente, mas ainda não avançou substancialmente de forma a viabilizar todo o seu potencial ontológico, epistemológico e metodológico (BOOTH e ROWLINSON, 2006). Defendemos que tal quadro pode ser alterado por meio da identificação do embate paradigmático que ocorre dentro da área de História e que, nesse processo de aproximação, transborda para a área de Administração. Identificar as visões provenientes do acirrado debate entre as perspectivas da história tradicional e da história nova no campo da Administração pode contribuir para: a) melhor compreensão dos fenômenos administrativos; b) formação de pesquisadores mais conscientes de seus caminhos de pesquisa e c) fortalecimento da interdisciplinaridade por meio da criação de vínculos mais profundos entre as áreas.

De forma a aprofundar essa discussão, optamos por enquadrar na classificação de Üsdiken e Kieser (2004) três distintas abordagens do pensar administrativo, relacionando-as com a discussão paradigmática de visões da história: (1) a história dos negócios ou empresarial (business history); (2) a história da gestão (management 
history); e (3) a história organizacional (organizational history). Cabe destacar que compartilhamos da ideia de que qualquer processo de classificação e ou categorização pode apresentar problemas, induzindo o leitor a identificar as relações estabelecidas como estanques e herméticas. No entanto, tal procedimento adquire certa relevância por permitir uma melhor visualização da problemática em questão, ou seja, das associações, modalidades e perspectivas históricas elencadas.

Este artigo estrutura-se em quatro seções. Após esta introdução, apresentamos os conceitos de história e historiografia a partir de duas historiografias diferentes: a perspectiva da história política mais tradicional em contraposição à perspectiva da nova história. $\mathrm{Na}$ terceira seção, identificamos as três abordagens escolhidas, vinculando-as às perspectivas historiográficas. $\mathrm{Na}$ última seção, discutimos possíveis contribuições do uso da perspectiva histórica nos estudos de Administração.

\section{PERSPECTIVA HISTÓRICA}

\section{História e historiografia}

Neste trabalho, assumimos a definição de história como sendo tanto uma série de acontecimentos quanto a narração dessa série de acontecimentos (VEYNE, 1971). Le Goff (1992) chama esse fenômeno de dualidade da história, ou seja, a história como história-realidade e história-estudo dessa realidade. Nesse cenário, tornase imprescindível (e conveniente) recorrer aos recortes para refletir sobre a história. Tais recortes podem assumir três formas: (1) recortes temporais (periodizações clássicas, como Pré-História, Idades Média ou Moderna); (2) recortes espaciais (recortes territoriais, como história continental, nacional ou regional, ou agrupamento da historiografia por nacionalidade, época); e (3) recortes temáticos (história política, dos eventos, econômica, social, entre outros) (BURKE, 1992).

Atrelado ao conceito de história, a historiografia ou a história da história - expressa as visões de mundo dos historiadores acerca de suas abordagens, objetos e problemas. Historiografia não é método, mas um ramo da ciência histórica que estuda a evolução da própria ciência histórica no desenvolvimento histórico global. Pode ser considerada como o equivalente a qualquer parte da produção historiográfica, ou seja, ao conjunto dos escritos dos historiadores acerca de um tema ou período histórico específico (LE GOFF, 1992).

A importância da historiografia está atrelada à ideia de que a história não é uma ciência do passado, mas a ciência dos homens no tempo cuja relevância reside na importância atribuída ao presente para a compreensão do passado (BLOCH, 2001). Assim, pensar história e historiografia implica considerar a práxis social do pesquisador e sua escolha de objetos de pesquisa, uma vez que a historiografia elege temas que falam mais de suas próprias inquietações e convicções do que de tempos memoráveis (SCHWARCZ, 2001).

Em consonância com essas ideias, a opção deste artigo é trabalhar com um enquadramento bem específico: a mudança paradigmática da história nova. Essa mudança na historiografia ocorreu na virada dos séculos XIX e XX, por meio do embate entre duas visões antagônicas: o paradigma iluminista ("moderno") da história tradicional política e o paradigma "pós-iluminista" da nova história (CARDOSO, 1997). Acreditamos que esse debate nos permite perceber melhor possíveis contribuições que a pesquisa histórica pode prover aos estudos organizacionais.

\section{Historiografia política tradicional versus nova história}

Segundo Burke (1997), desde Heródoto e Tucídides - os primeiros historiadores - a história tem sido escrita sob uma variada forma de gêneros, porém dentro de uma mesma visão conceitual. Mesmo sendo possível identificar continuidades e descontinuidades da história praticada por gregos e romanos naquelas dos eclesiásticos e escribas leigos da Idade Média, sua essência de retenção de certos eventos e de continuidade narrativa manteve-se quase intacta (FALCON, 1997). Era a história política tradicional, que, como mestra da vida - magistra vitae - e depositária da memória, tinha como função o ensinamento por meio de exemplos reais e ilustres. Caracterizada como a narrativa dos acontecimentos políticos e militares, apresentada como a história dos grandes feitos de grandes homens e legitimada por uma visão centralizada e institucionalizada do poder, a história política tradicional foi definindo e disseminando seus objetos, princípios e métodos mesmo diante de tentativas de contestação a esse tipo de narrativa.

Com o objetivo de tentar compreender esse processo (fortalecido, apesar das críticas, a partir do século XIX), Burke (1992; 2002) destaca duas possíveis explicações. Primeiro, os governos europeus, a partir do Renascimento, passaram a considerar a história como mecanismo de promoção da unidade nacional. A historiografia promove o Estado à condição de "objeto por excelência da produção histórica” (FALCON, 1997, p 
65), e, como resultado, pode-se afirmar que no século XIX os acontecimentos são sempre compreendidos como eventos políticos, e o poder é sempre o poder do Estado e de suas instituições, aparelhos e dirigentes.

A segunda explicação refere-se à ocorrência de uma revolução nas fontes e nos métodos históricos, que deixavam de utilizar as histórias e crônicas mais antigas como fontes, substituindo-as por registros oficiais do governo. Simultaneamente, os historiadores começaram a "trabalhar regularmente nos arquivos e elaboraram técnicas cada vez mais sofisticadas para avaliar a confiabilidade desses documentos" (BURKE, 2002, p. 17). Tratava-se de definir as diferenças entre a verdade histórica e a ficção literária por meio da separação dos fatos verdadeiros (que podem ser comprovados) e dos fatos falsos.

Segundo Le Goff (1992, p. 9), a história começou como história relato ou como história testemunho, como "a narração daquele que pode dizer 'eu vi, senti'. De forma a superar as limitações impostas por essa abordagem (o limite do meio século abrangido pelos historiadores que dele foram testemunhas e as limitações da transmissão oral do passado), a ciência histórica passou a priorizar a reunião de documentos escritos, transformando-os em testemunhos.

Assim, a constituição de bibliotecas e de arquivos (elaborados por meio de métodos de crítica científica) passava a fornecer os materiais da história. Nesse contexto, a história adquire legitimidade amparada por categorias relacionadas à objetividade e cientificidade. "A história é ciência e não arte, consistindo a tarefa do historiador não em evocar ou reviver o passado [...] mas sim em narrar/ descrever os acontecimentos deste passado tal como eles realmente se passaram" (FALCON, 1997, p. 66).

É o apogeu da história política - narrativa, cronológica, factual e linear - e, não por acaso, o inicio do processo de profissionalização da disciplina com a fundação dos primeiros institutos de pesquisa, revistas especializadas e departamentos universitários. O historiador, inserido nesse processo, era o indivíduo que dominava o método, tornando-se o veículo de escrita da verdade: autônomo, imparcial e neutro. Seus rígidos procedimentos metodológicos científicos em relação às fontes históricas priorizam as investigações sobre a importância da autenticidade documental. É por meio desse processo que o documento autêntico adquire o fundamento do fato histórico e, com base nessa suposição, alguns historiadores afirmam que não existe notícia histórica sem documentos e que, se dos fatos históricos não foram registrados documentos (gravados ou escritos), tais fatos se perderam (LEFEBVRE, 1981).
Como características principais dessa historiografia, podemos identificar: a) discurso histórico construído em função de uma epistemologia empirista; b) análises de curtos períodos temporais; c) foco no âmbito político e na atribuição de relevância aos eventos conjunturais e personagens específicos (história baseada em ideias e ações de alguns poucos agentes históricos individuais).

Durante as três primeiras décadas do século XX, manteve-se quase inalterada a hegemonia da historiografia política tradicional, começando o seu declínio somente a partir dos anos 1930 com a história social e a partir dos anos 1970 com a nova história.

O movimento rumo a um novo tipo de história foi iniciado e conduzido por dois professores da Universidade de Estrasburgo: Marc Bloch e Lucien Febvre, em 1929, com a publicação do primeiro número da revista dos Annales d'Histoire Économique et Sociale. Era a abertura da disciplina história às temáticas e métodos das outras ciências humanas por meio da formulação de novos problemas, novos métodos e novas abordagens da pesquisa histórica (CASTRO, 1997). A proposta dessa historiografia é ampliar o domínio historiográfico, assumindo a história como estudo do homem no tempo por meio da redefinição de conceitos fundamentais como documento, fato histórico e tempo.

No século XX, a historiografia renovada promove um profundo questionamento tanto da noção de fato histórico (não mais um objeto dado e acabado e sim construção do historiador) quanto da noção de documento (noção ampliada e não mais considerado algo objetivo e inocente). A própria ausência de documentos passa a ser significativa, pois elucida que estes são sempre produtos de uma sociedade que os fabricou segundo relações de dominação e poder.

Nesse sentido, os maiores problemas para os novos historiadores são exatamente os relacionados às fontes e aos métodos: "Quando os historiadores começaram a fazer novos tipos de perguntas sobre o passado, para escolher novos objetos de pesquisa, tiveram de buscar novos tipos de fontes, para suplementar os documentos oficiais" (BURKE, 1992, p. 25). Com relação ao tempo, contra a versão da época que define o passado como um dado rígido, não alterável, esses historiadores advogam a ideia da história como dominada pelo presente, onde toda história é história contemporânea. Dito de outra maneira, por mais afastados no tempo que pareçam estar os acontecimentos, na realidade, a história liga-se às necessidades e às situações de um presente onde tais acontecimentos têm ressonância.

Podem-se destacar como principais características 
dessa historiografia renovada: (a) uma narrativa com digressões e remissões; (b) a eventual análise de longos períodos temporais (longa história) ou "períodos históricos mais alargados e estruturas que se modificavam de maneira mais lenta e preguiçosa" (SCHWARCZ, 2001, p. 9); (c) maior flexibilização da investigação, voltandose aos campos social, econômico e cultural; e (d) maior relevância à interpretação de estruturas duradouras (CURADO, 2001; MARTINS, 2001).

Segundo Burke (1992), podem-se resumir em seis pontos os principais contrastes entre as duas historiografias. Primeiro, com relação aos objetos da história. No paradigma tradicional, a história diz respeito à política; na história nova, toda atividade humana pode ser objeto da história. Segundo, os historiadores tradicionais pensam na história como essencialmente uma narrativa dos acontecimentos; a nova história está mais preocupada com a análise das estruturas. Terceiro, a história tradicional oferece uma visão de cima, no sentido de que tem sempre se concentrado nos grandes feitos dos grandes homens, estadistas, generais ou eclesiásticos; os novos historiadores estão preocupados com a história vista de baixo, com as opiniões das pessoas comuns e sua experiência de mudança social. Quarto, segundo o paradigma tradicional, a história deveria ser baseada em documentos oficiais escritos; a história nova expõe as limitações desse tipo de documento, examinando maior variedade de evidências, atribuindo menor ênfase às fontes escritas e maior relevância ao uso da história oral, iconografia e vestígios arqueológicos (CARDOSO, 1997). Quinto, a história tradicional preocupa-se com as ações dos indivíduos, ao contrário da história nova, que considera relevantes movimentos coletivos e individuais. E por último, segundo o paradigma tradicional, a história é objetiva, e a tarefa única do historiador é apresentar aos seus leitores os fatos. Hoje em dia esse ideal é considerado irrealista. A história nova mostra a inevitabilidade da falta de isenção ao olhar sobre o passado, pois "só percebemos o mundo através de uma estrutura de convenções, esquemas e estereótipos, um entrelaçamento que varia de uma cultura para outra" (BURKE, 1992, p. 15).

Cabe ressaltar, ainda, o debate em torno dos usos e significados do conhecimento histórico e das diferentes relações entre poder e política para a compreensão do passado. A nova história tornou possível "a abertura para concepções novas e variadas a respeito de temas pouco frequentados pela historiografia: os poderes, os saberes enquanto poderes, as instituições supostamente não políticas, as práticas discursivas" (FALCON, 1997, p.
75). Inclusive para a própria história política, mediante o alargamento do interesse histórico (CASTRO, 1997). Poder e política passam ao domínio das representações sociais e de suas conexões com as práticas sociais, adquirindo relevância e prioridade questões acerca do simbólico (simbolismo, formas simbólicas, poder simbólico), das representações sociais ou coletivas, dos imaginários sociais, da memória (ou memórias coletivas), das mentalidades e das práticas discursivas associadas ao poder.

Essa discussão paradigmática - pertinente inicialmente ao campo da história - transborda para o pensar administrativo no momento em que começam a ocorrer apropriações da perspectiva histórica em administração. Acreditamos que essa incorporação não possa ocorrer de forma ingênua nem irresponsável, uma vez que cada posição ontológica e epistemológica assumida encaminha o pesquisador para distintas possibilidades de fontes, objetos, problemas e métodos e, portanto, a distintas tentativas de apreensão da realidade organizacional.

\section{PERSPECTIVA HISTÓRICA EM ADMINISTRAÇÃO}

A aproximação entre administração e história reflete pontos críticos do debate entre uma perspectiva histórica mais tradicional e uma perspectiva da história nova, discussão já identificada na seção anterior. Üsdiken e Kieser (2004) defendem que os pontos a favor da perspectiva histórica nos estudos organizacionais têm envolvido teóricos e pesquisadores em três posições distintas: uma posição suplementarista; uma posição integracionista; e uma posição reorientacionista.

De forma a aprofundar essa discussão, optamos - para fins deste trabalho - por enquadrar na classificação de Üsdiken e Kieser três distintas abordagens do pensar administrativo, relacionando-as com a discussão do corte paradigmático da história (historical turn), quais sejam: 1) a história dos negócios ou empresarial (business history); 2) a história da gestão (management history); e 3) a história organizacional (organizational history).

Ao proceder a tal enquadramento, algumas identificações foram possíveis. Primeiro, identificamos forte associação entre uma primeira etapa da história empresarial com características do paradigma da história tradicional e com a posição suplementarista. Já em um segundo momento, mais atual, a posição dessa abordagem é alterada, evidenciando aproximações com a posição integracionista. Ainda dentro do paradigma tradicional da história, identificou-se a história da gestão com a posição integracionista. Por último, a abordagem 
da história organizacional foi identificada com características do paradigma da história nova e com a posição reorientacionista.

\section{A posição suplementarista e a integracionista: história empresarial e história da gestão}

De acordo com Üsdiken e Kieser (2004), a posição suplementarista assume a construção teórica na qual a história pode prover contribuições significativas, sendo compreendida como potencial de confirmação e refino de teorias gerais, seleção de variáveis e geração de hipóteses em um contexto teórico. Segundo Sauerbronn e Faria (2006), essa posição deriva de duas proposições: (a) a atividade humana é inerentemente dinâmica; e (b) as motivações e ações humanas respondem sensivelmente a mudanças nas circunstâncias sociais e culturais. Assim, esta pode ser realizada, desde que condicionada e restrita aos seguintes aspectos: as proposições são sempre contextuais e explicariam as causas de circunstâncias únicas ou descontinuidades temporais.

Nessa perspectiva, mostra-se bastante apropriado o procedimento da análise diacrônica, que busca explicar as mudanças ao longo do tempo, ou seja, fatores que se mantêm, surgem ou desaparecem ao compararmos períodos históricos. Como exemplo de pesquisador nessa perspectiva, destacamos Goldman (1994), cuja argumentação é a de que a perspectiva histórica somente deve ser incorporada aos estudos organizacionais se o pesquisador assumir: (a) que existem princípios organizacionais que transcendem tempo e espaço; e (b) que dados comparativos históricos podem testar a capacidade de generalização e utilidade de uma teoria. Cabe ressaltar que a maior parte dos estudos pode ser enquadrada nessa perspectiva (como é o caso dos estudos sobre estratégia empresarial), sendo a história “(...) apenas mais uma variável de análise empírica a ser considerada no corpus de pesquisa" (VIZEU, 2007, p. 6).

Argumentamos que tal perspectiva está relacionada com a tradicional forma de se pesquisar a história empresarial: o estudo sistemático de firmas individuais com base em sua própria documentação (BOOTH e ROWLINSON, 2006). A história empresarial apresentase como a mais antiga abordagem que expressa a aproximação entre administração e história, e o seu desenvolvimento não ocorreu de forma linear, homogênea e sem rupturas.

Segundo Lobo (1997), apesar de os historiadores da atividade empresarial considerarem como precursores de sua área Say, Schumpeter e Pirenne, a história empresarial começou a ser desenvolvida nos EUA com a criação, em 1926, da Business History Society e, em 1928, do Journal of Economic Business History. Seu foco era o estudo isolado de empresas, sem integrá-las num contexto socioeconômico mais amplo.

Com uma perspectiva um pouco diferente, foi fundado, em 1944, o Centro de História Empresarial, em Harvard, com foco em história social. Talcolt Parsons, por exemplo, foi um pesquisador influente na formação teórica do centro, priorizando em suas pesquisas a capacidade gerencial e o prestígio social "de acordo com o reconhecimento pela sociedade da importância dos status ocupados pelos indivíduos" (LOBO, 1997, p. 218).

$\mathrm{Na}$ França e Inglaterra, a história empresarial adquire relevância apenas na década de 1950, mas também em uma perspectiva social. No Brasil, inicialmente a produção sobre história empresarial era uma pesquisa sem perspectiva geral, apenas com o foco na administração interna de determinada unidade de produção ou na exaltação do fundador da empresa.

Como atividade acadêmica, a história empresarial desenvolveu-se como uma ramificação da história econômica, utilizando profundos estudos de caso de corte longitudinal, com grandes recortes temporais. As fontes tradicionais dessa área - fontes escritas - consistem em cartas, memorandos, periódicos e contas em geral (LOBO, 1997).

A história empresarial só se amplia a partir da década de 1970, adquirindo características e linhas de pesquisa específicas. Para Lobo (1997), os pesquisadores brasileiros passam a focalizar o contexto socioeconômico e crescem as pesquisas de estudos de casos procurando entender: (a) as estratégias dos empresários; (b) questionando visões já consagradas pela historiografia sobre as origens da indústria; (c) o papel dos empresários; (d) as ações do Estado; (e) e respectivos órgãos de classe.

De forma a tentar mapear a produção acadêmica da área de história dos negócios, Curado (2001) a divide em três grandes subáreas. A primeira é a referente à história das empresas ou história corporativa (corporative history), geralmente narrativas acerca de empresas individuais, quase sempre comissionadas pelas próprias companhias pesquisadas (BOOTH e ROWLINSON, 2006). Essas narrativas podem ser utilizadas pelas empresas para fortalecer vínculos com funcionários e fornecedores - por meio de uma história de vida corporativa que expressa solidez, segurança financeira e princípios éticos e/ou com seus consumidores - por meio de um histórico de preocupação com o meio ambiente.

As histórias de empresas compreendem narrativas e relatos descritivos de suas trajetórias, sem preocupação 
com a análise da atuação da empresa no contexto empresarial geral, sem críticas aos seus respectivos modelos de desenvolvimento nem comparações com outras empresas. Por exemplo, recentemente, no caso brasileiro, a história das empresas vem sendo valorizada por meio da publicação de diversas obras comemorativas narrando a trajetória de empresas nacionais e multinacionais.

A segunda é a história do empreendedorismo. Essa linha de pesquisa - entrepreneurship business history - remonta aos anos 1940, destacando-se a atuação de Arthur Cole, que, em 1948, organizou em Harvard o Center for Research on Entrepreneurship e editou o periódico Explorations in Entrepreneurial History (JONAS \& WADHWANI, 2008). Inicialmente, o foco eram estudos que tentavam identificar as características e as causas das transformações históricas nas empresas, nas indústrias e nas economias, ou como as instituições do capitalismo industrial evoluíam. Assim, são analisadas trajetórias de empresas empreendedoras - não de indivíduos - e relacionam-se "com medidas de sucesso empresarial, as mais populares sendo comparações internacionais, melhorias de produtividade, lucratividade e adaptação às mudanças relacionadas à introdução de novas tecnologias" (CURADO, 2001, p. 4). Mais recentemente, passaram a enfatizar a mentalidade e a agência dos empreendedores no processo de mudança econômica.

Ainda dentro dessa abordagem, temos a terceira subárea de pesquisa, que contempla os estudos acerca da história da grande empresa. O principal expoente dessa abordagem é Alfred Chandler. Segundo McCraw (1998, p.17), antes dos seus estudos comparados, "a maioria das obras de história empresarial consistia em monografias sobre determinadas firmas ou indústrias". Chandler foi professor de história da administração na Graduate School of Business Administration, em Harvard, concentrando o seu trabalho de pesquisa nos temas relativos ao surgimento e ao papel da grande empresa em consonância com a formação do capitalismo moderno (PUGH e HICKSON, 2004). A perspectiva histórica apresenta-se importante e adquire relevância quando este questiona o que, no passado norte-americano, permitiu e favoreceu a mudança e a inovação: "O que deu aos empresários a oportunidade ou criou-lhes a necessidade de mudar o que estavam fazendo ou o modo de fazê-lo?" (CHANDLER, 1998, p. 35). A resposta encontrada foi a identificação da existência de fatores dinâmicos na história empresarial dos Estados Unidos, como território, recursos naturais, atitudes e valores culturais (contexto cultural e geográfico).

Segundo Sauerbronn e Faria (2006), pode-se conside- rar que essa obra representou um esforço de conceitualização e generalização de pesquisa histórica comparada, tendo como principais fundamentos: (a) a concentração no processo de mudança; (b) a importância dos fatos; (c) $a$ atenção à cronologia com ênfase em complexos eventos e transformações culturais. Foi a partir do trabalho de Chandler que historiadores empresariais passaram a focar temas como empreendedorismo, estruturas corporativas, vantagens competitivas e inovação tecnológica.

Segundo Harvey e Wilson (2007), atualmente a área de história empresarial vem adquirindo cada vez mais relevância, em particular após a criação, na Inglaterra e na Europa, de ativas associações profissionais de historiadores empresariais e seus encontros anuais, a Association of Business Historians (ABH) e a European Business History Association (EBHA). Em relação às perspectivas que orientam as pesquisas, os trabalhos empíricos sobre empresas isoladas com foco na administração interna diminuíram. Em seu lugar, na Inglaterra e nos Estados Unidos, desenvolve-se a história comparada de empresas, e, na França, a história empresarial numa perspectiva mais global.

Essa ruptura, proveniente dos desdobramentos mais atuais da história empresarial, faz com que os pesquisadores se afastem de uma posição suplementarista e se aproximem de uma posição integracionista, direcionando o seu foco tanto "nas intercessões e conjunções da análise histórica quanto no estudo de formas particulares de organização e processos, redefinindo o campo de estudo como sendo humanístico e científico ao mesmo tempo" (SAUERBRONN e FARIA, 2006, p. 6).

A posição integracionista também pode ser identificada na abordagem da história da gestão (management history). A ideia é que a análise histórica não substituiria as teorias existentes, mas enriqueceria a compreensão do contexto atual por meio de conexões com as disciplinas humanísticas. Adotar a posição integracionista significa reconhecer que eventos do passado atuam no presente, sendo úteis para a identificação e escolha de oportunidades atuais.

A história da gestão e a história empresarial coincidem em alguns aspectos, em particular no que se refere ao estudo das práticas de gestão. No entanto, a história do pensar acerca da gestão constitui-se um campo distinto, com pesquisas focadas em F. W. Taylor e a influência da administração científica (WREGE e HODGETTS, 2000), e em releituras críticas de versões já consagradas de práticas de gestão (COOKE, 1999).

Um dos fóruns mais relevantes com relação ao tema é a Management History Division (MHD), divisão da 
Academy of Management, que tem por objetivo pesquisar tanto o desenvolvimento histórico dos conceitos e práticas de gestão quanto o papel histórico desempenhado pelos gestores. De forma complementar, os resultados das pesquisas e os debates acerca do tema estão presentes nos eventos promovidos pela divisão - sendo o principal o encontro anual da AOM - e nos artigos publicados pelo seu periódico, o Journal of Management History.

Entre seus principais tópicos, destacamos: (a) avaliações históricas das consequências sociais da gestão; (b) novas análises acerca dos conceitos históricos estabelecidos; (c) o papel histórico das ciências comportamentais na emergência das práticas de gestão; (d) o desenvolvimento histórico da gestão em empresas nos dias de hoje; (e) análises históricas de filosofias de gestão; (f) formas de utilização de fontes históricas; ( $\mathrm{g}$ ) novos rumos em pesquisa histórica e em história oral; (h) a importância da perspectiva histórica em gestão internacional; e (i) aspectos históricos em controle da qualidade, cultura e saúde, e segurança no ambiente de trabalho, entre outros.

Cabe ressaltar que o posicionamento integracionista vai além do suplementarista, onde a história é um campo de teste ou um complemento na construção ou refino de teorias. Advoga-se, neste caso, o uso da história e da análise histórica como fontes de explanação generalistas e construção de teorias. O passado se transforma em uma variável, uma vez que as regularidades causais podem ser encontradas na história.

Um bom exemplo de pesquisador nessa vertente é Zald (1993, 1996), que propõe uma reconceitualização dos estudos organizacionais como um empreendimento humanístico no qual a história pode prover grande contribuição. Seus questionamentos perpassam a discussão acerca da construção de teorias gerais abstratas com tendências universalistas que ignoram modelos alternativos. Para ele, grande parte dos problemas das ciências sociais consiste no fato de elas não serem apenas ciências, mas também serem sociais. Ou seja, referem-se às questões dos homens e são influenciadas por épocas e contextos específicos.

Outro autor importante é Kieser (1994). Para este, existiriam pelo menos quatro boas razões para revitalizar a análise histórica em pesquisas organizacionais: (1) como as estruturas e os comportamentos presentes nas organizações refletem desenvolvimentos históricos culturalmente determinados, somente na história se pode encontrar resposta à questão de como valores são diferentes através das culturas; (2) como a identificação dos problemas organizacionais e dos remédios adequados não está livre de ideologia, ao confrontar as tendên- cias atualmente na moda com os desenvolvimentos do passado será possível identificar e superar preconceitos que caracterizam a apresentação dessas tendências; (3) a análise histórica nos ensina a interpretar as estruturas organizacionais existentes, não como sendo determinadas por leis, mas como resultado de decisões do passado: a análise histórica poder preparar a organização para melhor identificar e fazer melhor uso das oportunidades; e (4) ao confrontar as teorias com o desenvolvimento histórico, estas estariam sujeitas a um teste mais forte do que se confrontadas com dados de curto prazo.

\section{A posição reorientacionista: a história organizacional}

Com um foco diferente das abordagens anteriores, a história organizacional concentra-se em conceitos e concepções provenientes da teoria organizacional e das ciências sociais e humanidades. Seu foco de pesquisa é mais abrangente, englobando não somente estudos sobre o passado/futuro das organizações, mas estudos acerca do sentido do passado/futuro para as organizações; estudos dos processos organizacionais por trás das histórias corporativas oficiais (TAYLOR e FREER, 2002, BOJE e ROSILE, 2003) e as razões para que essas histórias sejam escolhidas e não outras. Em última análise, a ideia é historicizar as organizações contemplando as dimensões e clivagens de poder.

Um importante fórum de discussão de história organizacional é o periódico Management \& Organizational History, criado em 2006. A análise dos artigos publicados nos últimos três anos nos permite perceber a escolha de novos objetos de estudo no que se refere à perspectiva histórica em administração, como, por exemplo: (a) música e comunidade (KORCZYNSKI, PICKERING e ROBERTSON, 2008); (b) contos e produção do conhecimento (DUREPOS, MILLS e MILLS, 2008); (c) direitos humanos e organizações (COOKE e MILLS, 2008); (d) amizade, organização e tradição ocidental (FRENCH, 2007); (e) história dos conceitos e ideologias de gestão (COSTEA, CRUMP e HOLM, 2006); (f) história, historiografia e estudos organizacionais (JACQUES, 2006); entre outros.

Tendo em vista a posição ontológica e epistemológica de tais estudos, argumentamos que esse posicionamento (diferentemente dos dois anteriores) converge para a perspectiva reorientacionista, e ocorreu atrelado aos princípios de uma historiografia renovada. Esse relacionamento pode ser entendido, dentro de um contexto maior de aproximação entre historiadores e cientistas sociais na busca da superação do universalismo posi- 
tivista, por meio de um relativismo histórico-cultural cujo pressuposto básico é que diferentes culturas, em diferentes momentos históricos, representam diferentes significados e visões de mundo (VIZEU, 2007; 2010).

Tal posição defende o afastamento das aspirações das ciências sociais que estejam baseadas no modelo das ciências naturais e que condicionam posicionamentos do pesquisador sobre o que vem a ser a realidade organizacional. Ou seja, corresponde a uma redefinição epistemológica do campo e considera de forma mais radical o papel da história no campo da pesquisa organizacional. Em um sentido mais amplo, seria desafiar não só o caráter a-histórico das pesquisas, mas também as posições suplementarista e integracionista, que, apesar de representarem avanço, ainda se encontram fortemente ancoradas em uma visão mais tradicional e limitadora da história.

Essa terceira abordagem permite confrontar diferentes alternativas em termos de orientação teórica, metodologias e visões de mundo, priorizando um enfoque narrativo alinhado ao interesse mais amplo das orientações interpretativas e discursivas em oposição ao quadro científico tradicional. Esse movimento pode fazer parte de uma transformação maior na direção do discurso, associado à hermenêutica, à linguística, e congruente com posições ontológicas e epistemológicas dos estudos críticos em Administração.

\section{LIMITES E POSSIBILIDADES DA PERSPECTIVA HISTÓRICA}

Este trabalho buscou contribuir para o aprofundamento da utilização da perspectiva histórica em estudos de Administração no Brasil por meio da defesa de uma agenda reorientacionista que envolve, prioritariamente, crítica às teorias organizacionais com orientação a-histórica. Em consonância com pesquisadores dessa posição, acreditamos na existência de significativas contribuições da perspectiva histórica para o campo da Administração, em particular as provenientes das mudanças da história nova.

Ontologicamente, a historiografia renovada pode contribuir com o campo dos Estudos Organizacionais por abrir possibilidade a novas percepções e novas abordagens com relação aos seus objetos de estudo. Assumindo que a história é dominada pelo presente, conhecer a essência das diferentes realidades que coexistem no tempo e no espaço talvez permita aos pesquisadores da área de Administração uma percepção mais reflexiva acerca do seu pensar e agir no mundo. E mediante esse procedimento, pode o pesquisador se liberar da servidão intelectual, uma vez que "o mundo não é uma coleção de objetos que possamos contemplar do lado de fora [pelo contrário], estamos necessariamente no mundo e por ele somos constituídos" (GUERREIRO RAMOS, 1996, p. 107).

Epistemologicamente, pode-se desafiar o caráter a-histórico e determinístico das pesquisas e defender a relação entre história e administração como forma de confrontar diferentes alternativas em termos de orientação teórica, priorizando um enfoque narrativo alinhado ao interesse mais amplo de orientações interpretativas e discursivas em oposição ao quadro científico tradicional. Uma maior preocupação com a busca da historicidade do espaço organizacional reflete-se na procura pela existência de um contexto específico para todos os acontecimentos e todos os fenômenos. E isso tanto em relação aos objetos de estudo quanto em relação aos pesquisadores.

Assumindo que o que é oficialmente definido como passado - o passado social formalizado - "é e deve ser claramente uma seleção particular da infinidade daquilo que é lembrado ou capaz de ser lembrado" (HOBSBAWN 2007 , p. 22), tornam-se fundamentais as tentativas de identificação de quais aspectos desse passado foram ou serão selecionados. E por quem. Ou seja, torna-se possível identificar o contexto do processo de tomada de decisão e de definição de regras, desvelando o componente ideológico presente nas escolhas, que, mediante a justificativa de uma racionalidade técnica neutra, limita - ou quase anula - possibilidades de alternativas. Não é à toa que alguns dos principais pesquisadores que propõem o resgate da perspectiva histórica em Estudos Organizacionais estão vinculados aos estudos críticos em Administração, como Mayer Zald, Roy Jacques, Gibson Burrell, Michael Rowlinson e Behlul Üsdiken.

Metodologicamente, problemas de pesquisa podem ser estudados por meio de novas e diferentes fontes históricas, ampliando tanto a noção de objeto de pesquisa quanto a noção de documento. A historiografia da história nova permite que o pesquisador se desloque do "porão para o sótão", metáfora usada para expressar a mudança de preocupações da base socioeconômica (da vida material) para os processos mentais, o cotidiano e as suas representações (VAINFAS, 1997).

Com relação à história empresarial, por exemplo, apenas a análise dos documentos organizacionais escritos - que auxiliam e fornecem evidências - é insuficiente para a compreensão do objeto administrativo. Os registros oficiais em geral expressam o ponto de vista oficial. Torna-se necessária - para o estudo histórico em admi- 
nistração - a superação da metodologia tradicional de pesquisa histórica, uma vez que: "Os livros de atas, apesar de fornecerem informações sobre diversas decisões, não explicam como essas decisões foram implementadas, e quais foram os critérios e subsídios no processo de tomada das decisões (...) os relatórios anuais dão uma visão do conjunto das atividades da empresa e de suas conjunturas de curto prazo, porém não informam como estas atividades são realizadas e qual será a forma de implementação dos objetivos do período seguinte (...)" (CURADO, 2001, p. 5).

Ao mesmo tempo, a aplicação da pesquisa histórica enquanto método de análise empírica e analítica - atrelada a novos objetos como símbolos, imaginário social e coletivo, memória, memória organizacional, práticas discursivas e narrativas - descortina as relações de poder inerentes à reprodução ideológica dominante que tende a naturalizar o pensar e o agir organizacional. Tal processo permite o reconhecimento de que a construção de teorias e de pesquisas não são um processo puramente metódico e definido por regras, mas também (e principalmente) um compromisso ideológico, político e moral por meio do qual se cria e se recria escolhido objeto de estudo.

Cabe ressaltar, todavia, alguns limites a essa abordagem. Talvez o limite mais significativo esteja vinculado à discussão acerca do que é a realidade e como esta pode ser apreendida pelo pesquisador. Assumir que a realidade é sempre construída por meio de um olhar atribuído de sentido (episteme) que a capta para se transformar em conhecimento implica considerar que díspares olhares podem variar de pesquisador para pesquisador em função das suas escolhas (sempre políticas) de pesquisa: seus objetos, seus problemas e suas abordagens.

O limite estabelece-se, exatamente, quando nos deparamos com um processo de hegemonização do conhecimento por um paradigma dominante - no caso da área de Administração pelo funcionalismo sociológico - que deslegitima e destrói a riqueza dos múltiplos olhares ao: (a) propor leis universais que regem os fenômenos observáveis; (b) procurar explicar e predizer o que acontece no mundo social, buscando regularidades e relacionamentos causais entre seus elementos constituintes; (c) considerar as organizações como estruturas estáticas; (d) aplicar modelos e métodos das ciências naturais ao estudo de assuntos humanos; e (e) buscar revelar a dimensão trans-histórica da organização formal por meio de padrões regulares de comportamento organizacional. A forte influência dessa visão de mundo, dominante no campo da Administração, reflete-se tanto na prática acadêmica de pesquisadores quanto na prática dos gestores organizacionais que adotam modelos e teorias administrativas estrangeiras.

Outros limites podem ser identificados no que se refere ao uso da metodologia histórica por pesquisadores de outras áreas. Apesar de existir tanto um debate permanente entre as áreas que compõe as ciências sociais quanto o não reconhecimento de fronteiras estritas $\mathrm{e}$ definitivas entre elas, tal utilização deve ser feita com rigor, de forma a não incidir em erros comuns, como, por exemplo, os apontados por Vizeu (2010, p. 39): "O universalismo - a concepção do fenômeno organizacional contemporâneo como sendo típico de qualquer organização ao longo da história - e o presentismo - o tratamento descontextualizado dos fenômenos organizacionais".

Por fim, na tentativa de resumir a argumentação defendida neste estudo, a perspectiva histórica da historiografia renovada e inserida numa posição reorientacionista nos possibilita: (1) refletir sobre a práxis social do pesquisador, uma vez que cada época seleciona novos temas que, no fundo, falam mais de suas próprias inquietações e convicções do que de tempos memoráveis; (2) considerar novas fontes, novos problemas e novas abordagens, uma vez que a tomada de consciência da construção social do fato histórico e da não inocência do documento descortina os processos de manipulação que se manifestam em todos os níveis da constituição do saber histórico e administrativo; e (3) perceber que novas perguntas podem deslocar o foco de análise do exógeno para o local, o que pode contribuir para o desenvolvimento de análises mais críticas sobre ideologias administrativas correntes.

Como sugestão para pesquisas futuras, cabe aqui chamar a atenção para alguns exemplos de tópicos de estudo em organizações no contexto brasileiro (de forma a complementar os tópicos identificados nas três abordagens elencadas) que poderiam utilizar o referencial proposto, contribuindo para elevar a relevância da pesquisa na área. Segundo Vizeu (2007; 2010), torna-se importante a elaboração de uma agenda que contemplasse as seguintes sugestões de temas: (a) estudos sobre a história do pensamento administrativo brasileiro; (b) estudos históricos sobre ideologias e discursos associados a práticas organizacionais; e (c) estudos sobre história corporativa e empresarial no Brasil. De forma complementar, Mascarenhas e Vasconcelos (2009) sugerem a utilização da abordagem histórica (nesse caso, da abordagem histórico-estrutural) de forma a melhor compreender a dinâmica da cultura organizacional. É bom lembrar que tais exemplos não esgotam as possibilidades de utilização da abordagem histórica. 
Por fim, gostaríamos de sugerir um último tema: os estudos acerca da cultura corporativa e construção da memória social. Nenhum diálogo acerca do passado e do presente é neutro, uma vez que exprime um sistema de atribuição de valores. Como nos lembra Ricœur (2007), tanto o excesso quanto a escassez de memória (e do interesse pela memória) são representativos de alguma coisa. Assim, pode-se argumentar que discutir a memória enquanto pauta dos estudos organizacionais significa, entre outras coisas, resgatar a perspectiva histórica e problematizar a opção das organizações do que lembrar - e do que esquecer. Trata-se aqui dos usos e abusos aos quais se presta a memória enquanto atividade exercida - prática - com a intenção de representar em verdade as coisas passadas (RICCEUR, 2007).

\section{NOTA DA REDAÇÃo}

Artigo originalmente apresentado no EnANPAD 2009 e submetido à RAE em regime de fast-track.

\section{REFERÊNCIAS}

BERJARANO, V. C; PILATTI, L. A; FRANCISCO, A. C; OLIVEIRA, A. C. A evolução das teorias administrativas à luz da sociologia de Norbert Elias. IX SIMPÓSIO INTERNACIONAL PROCESSO CIVILIZADOR. Ponta Grossa, Paraná, 2005.

BLOCH, M. Apologia da história ou o ofício do historiador. Rio de Janeiro: Jorge Zahar, 2001

BOJE, D; ROSILE, G. Life imitates art: Enron's epic and tragic narration. Management Communication Quarterly, v. 17, n. 1, p. 85-125, 2003.

BOOTH, C; ROWLINSON, M. Management and organizational history: prospects. Management \& Organizational History, v. 1, n. 1, p. 5-30, 2006.

BURKE, P. História e teoria social. São Paulo: Unesp, 2002.

BURKE, P. A escola dos Annales: 1929-1989. São Paulo: Unesp, 1997.

BURKE, P. Abertura: a nova história, seu passado e seu futuro. In: BURKE, P. (Org) A escrita da história: novas perspectivas. São Paulo: Unesp, 1992.

CARDOSO, C. F. História e paradigmas rivais. In: CARDOSO, C. F; VAINFAS, R. Domínios da história: ensaios sobre teoria e metodologia. Rio de Janeiro: Elsevier, 1997.

CARRIERI, A. P; PIMENTEL, T. D; CABRAL, A. C. A. O discurso e a sua análise no enfoque foucaultiano da formação discursiva: um método de pesquisa em estudos organizacionais. Gestão e Organizações, Recife, v. 3 , n. 2, p. 111-124, 2005
CASTRO, H. História social. In: CARDOSO, C. F; VAINFAS, R. Domínios da história: ensaios sobre teoria e metodologia. Rio de Janeiro: Elsevier, 1997.

CHANDLER, A. Ensaios para uma teoria histórica da grande empresa. Rio de Janeiro: FGV, 1998

CLARK, P; ROWLINSON, M. The treatment of history in organization studies: towards an "historic turn"? Business History, v. 46, n. 3, p. 331 352,2004 .

COOKE, B. Writing the left out of management theory: the historiography of the management of change. Organization, v.6, n.1 p. 81-105, 1999

COOKE, B; MILLS, A. J. The right to be human and human rights: Maslow, McCarthyism and the death of humanist theories of management. Management \& Organizational History, v.3, n.1 p. 27-47, 2008.

COSTEA, B; CRUMP, N; HOLM, J. Conceptual history and the interpretation of managerial ideologies. Management \& Organizational History, v. 1, p. 159-175, 2006.

CURADO, I. Pesquisa historiográfica em administração: uma proposta mercadológica. In: ENCONTRO NACIONAL DA ASSOCIAÇÃO NACIONAL DOS PROGRAMAS DE PÓSGRADUAÇÃO EM ADMINISTRAÇÃO, 25, 2001, Campinas. Anais. Campinas: ANPAD, 2001

DUREPOS, G; MILLS, A. J; MILLS, J. H. Tales in the manufacture of knowledge: writing a company history of Pan American World Airways. Management \& Organizational History, v.3, n. 1, p. 63-80, 2008.

FALCON, F. J. C. História e poder. In: CARDOSO, C. F; VAINFAS, R. Dominios da história: ensaios sobre teoria e metodologia. Rio de Janeiro: Elsevier, 1997.

FALCON, F. J. C. A Identidade do historiador. In: SIMPÓSIO NACIONAL DA ASSOCIAÇÃO NACIONAL DE HISTÓRIA, 28, 1995, Recife. Anais. Recife: ANPUH, 1995

FRENCH, R. Friendship and organization: learning from the western friendship tradition. Management \& Organizational History, v.2, n.3, p. 255-272, 2007.

GIBSON, J. W; HODGETTS, R. M; HERRERA J. M. Management history gurus of the 1990s: their lives, their contributions. Journal of Management History, v. 5, n. 6, p. 380-397, 1999

GOLDMAN, P. Searching for history in organizational theory: comment on Kieser. Organization Science, v. 5, n. 4, p. 621-623, 1994.

GUERREIRO RAMOS, A. A redução sociológica. Rio de Janeiro: UFRJ, 1996

HARVEY, C; WILSON, J. Redefining business history: an editorial statement. Business History, v. 49, n. 1, p. 1-7, 2007.

HOBSBAWN, E. Sobre história. São Paulo: Companhia das Letras, 2007.

JACQUES, R. S. History, historiography and organizational studies: the challenge and the potential. Management \& Organizational History, v. 1, n.1, p. 31-49, 2006. 
JAIME JR, P. O grupo de pesquisas em culturas empresariais: notas etnográficas sobre um encontro de saberes. Revista de Administração Pública, v. 35, n. 3, p. 153-179, 2001.

JONES, G; WADHWANI, D. Entrepreneurship. In: JONES, G; ZEITLIN, J. The Oxford handbook of business history. Oxford: Oxford University Press, 2008. p. 501-528.

KIESER, A. Why organization theory needs historical analyses? Organization Science, v.5, n.4, p. 608-620, 1994.

KORCZYNSKI, M; PICKERING, M; ROBERTSON, E. The last British work songs: Music, community and class in the Kent hop fields of the early-mid 20th century. Management \& Organizational History, v. 3, n. 1, p. 81-102, 2008.

LACOMBE, B. M. B. A cultura organizacional e as novas relações de trabalho: subsídios para análise do caso brasileiro. In: ENCONTRO DE ESTUDOS ORGANIZACIONAIS DA ASSOCIAÇÃO NACIONAL DOS PROGRAMAS DE PÓSGRADUAÇÃO EM ADMINISTRAÇÃO, 1, 2000, Curitiba, Anais. Curitiba: ENEO, 2000.

LE GOFF, J. História e memória. Campinas: Unicamp, 1992.

LEFEBVRE, G. O nascimento da moderna historiografia. Lisboa: Sá da Costa, 1981.

LOBO, E. História Empresarial. In: CARDOSO, C. F; VAINFAS, R. Domínios da história: ensaios sobre teoria e metodologia. Rio de Janeiro: Elsevier, 1997.

MAIELLI, G. Counterfactuals, superfactuals and the problematic relashionship between business management and the past. Management \& Organizational History, v. 2, n. 4, p. 275-294, 2007.

MAIELLI, G; BOOTH, C. Counterfactual history, management and organizations: reflections and new directions. Management $E$ Organizational History, v. 3, n. 1, p. 49-61, 2008.

MARTINS, P. E. M. A reinvenção do sertão: a estratégia organizacional de Canudos. Rio de Janeiro: FGV, 2001.

MASCARENHAS, A. O; VASCONCELOS, F. C. What does Captain Cook have to tell us about culture? Contributions for a structural and historical approach to culture and organizations. International Journal of Cross Cultural Management, v. 9, n. 3, p. 323-338, 2009.

MCCRAW, T. K. Introdução. Alfred Chandler: ensaios para uma teoria histórica da grande empresa. Rio de Janeiro: FGV, 1998. 342 p.

MISOCKZY, M. C. A. Leituras enamoradas de Marx, Bourdieu e Deleuze: indicações para o primado das relações nos estudos organizacionais. In: VIEIRA, M. M. F; ZOUAIN, D. M. (Org) Pesquisa Qualitativa em Administração. Rio de Janeiro: FGV, p. 71- 96, 2004.

MOTTA, F. C. P; ALCADIPANI, R; BRESLER, R. B. O estrangeiro e o mundo organizacional. In: ENCONTRO DE ESTUDOS ORGANIZACIONAIS DA ASSOCIAÇÃO NACIONAL DOS PROGRAMAS DE PÓSGRADUAÇÃO EM ADMINISTRAÇÃO, 1, 2000, Curitiba, Anais. Curitiba: ENEO, 2000.

PUGH, D. S; HICKSON, D. J. Os teóricos das organizações. Rio de Janeiro: Qualitymark, 2004.
REED, M. Teorização organizacional: um campo historicamente contestado. In: CLEGG, S; HARDY, C; NORDY, W; CALDAS, M; FACHIN, R; FISCHER, T. (Eds) Handbook de estudos organizacionais. V. 1. São Paulo: Atlas, 1999. p. 61-98.

RICCEUR, P. A Memória, a História e o Esquecimento. Campinas: Unicamp, 2007

ROWLINSON, M; PROCTER, S. Organizational culture and business history. Organization Studies, v. 20, n. 3, p. 369-396, 1999.

SAUERBRONN, F. F; FARIA, A. A utilização do método histórico em pesquisa acadêmica de marketing. In: ENCONTRO DE MARKETING DA DA ASSOCIAÇÃO NACIONAL DOS PROGRAMAS DE PÓSGRADUAÇÃO EM ADMINISTRAÇÃO, 2, 2006, Rio de Janeiro, Anais. Rio de Janeiro: EMA, 2006.

SCHWARCZ, L. M. Prefácio. In: BLOCH, M. Apologia da história ou o ofício do historiador. Rio de Janeiro: Jorge Zahar, 2001.

TAYLOR, B. C; FREER, B. Containing the nuclear past: the politics of history and heritage at the Hanford Plutonium Works. Journal of Organizational Change Management, v. 15, n. 6, p. 563-588, 2002.

TUCHMAN, G. Historical social science: methodologies, methods, and meanings. In: DENZIN, N. K; LINCOLN, Y. S. (Eds) Handbook of Qualitative Research. London: Sage, 1994.

ÜSDIKEN, B; KIESER, A. Introduction: history in organization studies Business History, v. 46, n. 3, p. 321-330, 2004.

VAINFAS, R. História das mentalidades e história cultural. In: CARDOSO, C. F; VAINFAS, R. Domínios da história: ensaios sobre teoria e metodologia. Rio de Janeiro: Elsevier, 1997. p. 127-162.

VEYNE, P. Como se escreve a história. Lisboa: Edições 70, 1971.

VIZEU, F. Em algum lugar do passado: contribuições da pesquisa histórica para os estudos organizacionais brasileiros. In: ENCONTRO NACIONAL DA ASSOCIAÇÃO NACIONAL DOS PROGRAMAS DE PÓSGRADUAÇÃO EM ADMINISTRAÇÃO, 31, 2007, Rio de Janeiro. Anais. Rio de Janeiro: ANPAD, 2007

VIZEU, F. Potencialidades da análise histórica nos estudos organizacionais brasileiros. RAE-revista de administração de empresas, v. 50, n. 1, p. $37-$ 47,2010

ZALD, M. N. More fragmentation? Unfinished business in linking the social sciences and the humanities. Administrative Science Quarterly, v. 41, n.2, p. 251-261, 1996.

ZALD, M. N. Organization studies as a scientific and humanistic enterprise: toward a reconceptualization of the foundations of the field Organization Science, v. 4, n. 4, p. 513-528, 1993.

WREGE, C. D; HODGETTS, R. M. Frederick W. Taylor's 1989 pig iron observations: examining fact, fiction, and lessons for the new millennium. Academy of Management Journal, v.43, n.6, p. 1283-1291, 2000. 